\title{
Effect of organic solvents in morphology and mechanical properties of electrospun polyvinylpyrrolidone fibers
}

\author{
Diego Narváez $z^{\mathrm{a}}$, Christian Narváez-Muñoz ${ }^{\mathrm{a}}$, Nathaly Villacís ${ }^{\mathrm{a}}$, Karla Vizuete ${ }^{\mathrm{b}}$, Carlos Arroyo ${ }^{\mathrm{b}, \mathrm{c}}$ \\ ${ }^{a}$ Departamento de Ciencias de la Energía y Mecánica, Universidad de las Fuerzas Armadas ESPE, Sangolquí, Ecuador \\ ${ }^{\text {b }}$ Centro de Nanociencia y Nanotecnología, Universidad de las Fuerzas Armadas ESPE, Sangolquí, Ecuador \\ ${ }^{a}$ Departamento de Ciencias Exactas, Universidad de las Fuerzas Armadas ESPE, Sangolquí, Ecuador \\ danarvaez@espe.edu.ec, cpnarvaez1@espe.edu.ec, cnvillacis@espe.edu.ec, ksvizuete@espe.edu.ec, ccarroyo@espe.edu.ec
}

\begin{abstract}
Resumen - En el presente trabajo, se utilizó la técnica de electrospinning para obtener fibras para caracterización mecánica. El polímero polivinilpirrolidona (PVP) fue combinado con solventes orgánicos (etanol y dimetilformamida (DMF)) para generar soluciones y determinar los parámetros apropiados para obtener fibras con la mejor morfología y mejores propiedades mecánicas. La formulación de soluciones se basó en investigaciones previas, para encontrar el porcentaje adecuado de solvente y PVP. Se elaboraron varias soluciones, variando los diferentes parámetros, como voltaje, flujo, distancia aguja-colector. Para determinar si las muestras eran aceptables, se midió el diámetro en un microscopio electrónico de barrido (SEM por sus siglas en inglés). Se midió el módulo elástico para las fibras con mejor aspecto. Las propiedades mecánicas fueron medidas en un microscopio de fuerza atómica (AFM por sus siglas en inglés) con el método de contacto de Hertz, y los datos fueron aproximados a su modelo matemático. Las soluciones que tuvieron las mejores propiedades mecánicas fueron: etanol - 8\% PVP, DMF - 14\% PVP, $70 \%$ etanol - 30\% DMF - 8\% PVP, con diámetros en el rango de los micrómetros de 1.6, 1.22 y $1.35 \mu \mathrm{m}$, y un módulo elástico de 40.08 MPa, 8.8 MPa y $32.78 \mathrm{MPa}$, respectivamente. Se llevó a cabo un análisis de todos los parámetros que afectan el proceso y la influencia de los solventes basados en los datos de módulo elástico.
\end{abstract}

Palabras Claves- electrospinning, electrospun, PVP, módulo elástico, módulo de Youg

Abstract-In this work, the electrospinning technique was used to obtain fibers for mechanical characterization. polyvinylpyrrolidone (PVP) was combined with organic solvents (ethanol and dimethylformamide (DMF)) to generate solutions, looking for the appropriate parameters to obtain fibers with the best morphology and the best mechanical properties. Starting from previous investigations to find the adequate percentages of solvent and PVP, several solutions were made, varying the different parameters like voltage, flow, tip collector distance. Seeking to obtain acceptable samples, the diameter was measured in a scanning electron microscope (SEM). The elastic modulus was measured for the fibers with the best aspect. Mechanical properties were measured in an atomic force microscope (AFM) with the Hertz contact method and the data were approximated to its mathematical model. The solutions that resulted in the best morphological properties were: ethanol - $8 \%$ PVP, DMF - 14\% PVP, $70 \%$ ethanol - $30 \%$ DMF - 8\% PVP, with diameters in the micrometer range of 1.6, 1.22 and 1.35 respectively, and elastic modulus of 40.08 MPa, 8.8 MPa and 32.78 MPa correspondingly. An analysis of all the parameters influencing the process was performed and an analysis of the influence of the solvents, based on the data of the elastic moduli was carried out.

Keywords-electrospinning, electrospun, PVP, elastic modulus, Youg's modulus.

\section{INTRODUCTION}

The electrospinning technique, in which an electric field is applied between a needle and a collector to obtain fibers, has been extensively applied in medicine and engineering to produce fibers with a variety of shapes and sizes from different polymeric solutions and replicate natural structures, such as spider nets [1,2]. In this process, a conductive polymeric solution is pumped at very low rates through the needle, and when repulsive electrostatic forces have overcome surface tension, a jet is created [2]. As the stream travels to the collector through the air, the solvent evaporates, leaving a path of charged fibers, which can be gathered in the collector [3]. Generally, electrospinning fibers are characterized by their shape and size; they have to be uniform, without beads and maintain a constant diameter along the path they follow for the process to be considered successful [2]. The majority of studies regarding electrospinning fibers have analyzed how the parameters of the machine, like feed rate, voltage, and distance to the collector, affect the morphology of the fibers, while leaving aside the solvent used in the polymeric solution, which could also influence fibers' configuration.

From the studies that do have analyzed the effect of solvents, they focus on the fibers' structure and morphology. Megelski, S. et al. [4] studied how the surface morphology of fibers of polycarbonate (PC), polyethylene oxide (PEO), and polymethyl methacrylate (PMMA) changes when using different solvents, being carbon disulfide (CS2), toluene, and tetrahydrofuran / dimethylformamide (THF/DMF). Son, W. K. et al. [5] carried out an analysis with PEO and different solvents, being chloroform, ethanol, DMF, and water. They found out that for higher values of the dielectric constant of the solvent, thinner fibers were obtained. Wannatong, L., Sirivat, A., \& Supaphol, P. [6] used acetic acid, acetonitrile, m-cresol, toluene, THF, and DMF in combination with PS to produce electrospun fibers. They concluded that higher density and boiling point of the solvent resulted in greater diameters, and that DMF gave the highest productivity and optimal morphological characteristics. Similarly, in the work of Jarusuwannapoom, T. et al. [7], eighteen solvents were tested with PS to produce electrospinning fibers. They arrived to the conclusion that dipole moment of the solvent and conductivity of both the solvent and the resulting solution must be high enough to achieve electrospinnable solutions. 
$\mathrm{Wu}, \mathrm{X}$. et al. [8] tested ethyl cellulose (EC) with different concentrations of THF and dimethylcetamide (DMAc) and concluded that the composition of the solvent affects the diameter and distribution of fibers; particularly, adding DMAc decreases the diameter, and the morphology changes for different compositions. In the study conducted by Choktaweesap, N. et al. [9], fibers of gelatin with different solvents were fabricated. They observed that dimethyl sulfoxide (DMSO) and ethylene glycol (EG) gave reduced diameters in comparison to glacial acetic acid (AA). Casasola, R. et al. [10] showed that poly lactic acid (PLA), with a proportion $60 / 40 \mathrm{v} / \mathrm{v}$ of acetone (AC)/DMF produced thinner nanofibres than other configurations; also, they found that by increasing the amount of acetone, the diameter of nanofibers decreased.

None of the studies mentioned have investigated how the mechanical properties of the fibers are modified when the solvent changes. Iwamoto, S. et al. [11] used an atomic force microscope (AFM) to determine the elastic modulus of cellulose fibers, but a relation to the solvent was not established. Only Veleirinho, B. et al. [12], in their work with solutions with polyethylene terephthalate (PET) and trifluoroacetic acid (TFA)/dichloromethane (DCM) state that the characteristics of the solvent influence mechanical properties of the nanofibrous mats. The elastic modulus, tensile strength, and elongation of the bulk material were measured for different configurations of TFA/DCM tested, concluding that the fibers with the largest modulus were the ones that used 70\% TFA, while the ones with $40-50 \%$ TFA were the smallest. They also showed that for a higher amount of DCM, the mechanical performance decreases.

Determining the best solvent for fibers becomes of crucial importance, as well as establishing a connection between mechanical properties and solvent in electrospinning fibers, which is the aim of this work.

\section{MethodOLOGY}

\section{A. Materials}

All the materials used for this research were of analytical grade. Polyvinylpyrrolidone, PVP K90, was purchased from XI'AN LUKEE BIO-TECH CO. LTD, a Chinesecompany. Ethanol and Dimethylformamide were bought in "La Casa del Químico”, in Quito, Ecuador.

\section{B. Electrospinning setup}

The electrospinning machine was assembled at the laboratory and has the following parts: a Genvolt voltage supply, model 73030, which can reach up to $30 \mathrm{kV}$, a Just Infusion syringe pump, model NE-300, an aluminum collector, a CCD camera, and a lamp. A NIPRO plastic syringe of $10 \mathrm{ml}$ was used to store the PVP solution, and a $0.4 \mathrm{~mm}$ diameter needle was used as the charged capillary. The general setup to obtain electrospray particles was taken from [13]. All electrospinning processes were carried out under laboratory conditions (room temperature and humidity). Different weight percentages were tested for the solutions in the electrospinning process. Using ethanol as the solvent, the weight percent of PVP was varied from $4 \%$ to $10 \%$. For DMF, PVP was varied from $8 \%$ to $14 \%$. A combination of both of the solvents was also used, with a ratio of 70/30 in weight for ethanol/DMF, and 8\% of PVP.
The feed rate, distance from needle's tip to collector, and voltage were modified for every solution tested until achieving a stable jet.

\section{Morphology of fibers}

Morphology and size of electrospinning fibers were measured in a Mira Tescan 3XM field-emission gun scanning electron microscope (FEG-SEM). All samples taken to the FEG-SEM were covered with a conductive layer of gold, using a Quorum Q150 ES sputtering evaporator. Low $(\times 1000)$, medium $(\times 5000)$ and high $(\times 10000)$ micrographs were taken to observe distribution, uniformity, and diameter of the fibers.

\section{Elastic modulus}

The mechanical properties of the fibers were measured in a MFP-3D Infinity Asylum Research atomic force microscope (AFM) with a $20 \mathrm{~nm}$ silicon tip coated with $\mathrm{Ti} / \mathrm{lr}$. The Sader method was used to determine the spring constant and the tip sensitivity, and calibrate the machine. The Hertz contact model was used to obtain the force plots, with a scanning area of $10 \mu \mathrm{m} \times 10 \mu \mathrm{m}$, and a resolution of $8 \times 8$ pixels. The AFM has its own software, AR 15.06.109, which analyzes the data gathered and gives an approximate value of the Young's modulus.

\section{ANALYSIS OF RESULTS}

\section{E. Morphological analysis}

Tables I-III show the parameters employed, mean diameter, and uniformity of fibers, obtained for the solutions of ethanol, DMF, and a combination of the two, respectively. The following nomenclature was used: $\mathrm{Q}=$ feed rate $[\mathrm{ml} / \mathrm{h}], \mathrm{D}=$ distance to collector $[\mathrm{cm}], \mathrm{V}=$ voltage [V], $\mathrm{d}=$ mean diameter $[\mu \mathrm{m}], \mathrm{B}=$ defect for beads, Bif = defect for bifurcated fibers, DD = defect for different diameters, $\mathrm{C}=$ defect for low concentration of fibers. In these tables, for each solvent (or combination of solvents) used, there is one configuration in weight percent in which fibers have the best properties. In these cases, not only the weight percent was adequate, but also the machine parameters used, like feed rate, distance to collector and voltage. As far as the defects is concerned, when the feed rate is too high, beads can appear, as is the case of the first sample, shown in Fig. 1, which corresponds to ethanol with $4 \%$ wt PVP. If the weight percent of the solution is too low, bifurcated fibers can show up, as in the case of the fourth sample, with ethanol and 6\% PVP, shown in Fig. 2. When the distance from needle's tip to collector is too large, the number of fibers deposited in the collector decreases, as seen in the tenth sample, in Fig. 3, for DMF and 12\% PVP. What is also noticeable from Tables I-III is that as the weight percent increases, so does the diameter. For all the successful fibers, the Young's modulus was measured. In the case of the fibers without defects, their micrographs are shown in Fig. 4-6.

\section{F. Mechanical Analysis}

Samples 5, 11, and 14, with ethanol and 8\% wt PVP, DMF and 14\% wt PVP, and ethanol with DMF in 70/30 ratio and $8 \%$ wt PVP, respectively, were analyzed to find the elastic modulus of the fibers. 
TABLE I

PARAMETERS AND RESULTS FOR THE ETHANOL SOLUTIONS

\begin{tabular}{|c|c|c|c|c|c|c|}
\hline No. & $\begin{array}{c}\text { PVP } \\
\text { w/yt }\end{array}$ & Q & D & V & d & Defects \\
\hline 1 & 4 & 5 & 12 & 5 & 0.84 & B, Bif C \\
\hline 2 & 4 & 5 & 20 & 5.5 & 1.16 & B, Bif C \\
\hline 3 & 6 & 5 & 15 & 5 & 1.1 & B, Bif \\
\hline 4 & 6 & 5 & 20 & 5.5 & 1.48 & Bif \\
\hline 5 & 8 & 4 & 15 & 6 & 1.6 & --- \\
\hline 6 & 10 & 5 & 17 & 6 & 3.62 & C \\
\hline
\end{tabular}

TABLE II

PARAMETERS AND RESULTS FOR THE DMF SOLUTIONS

\begin{tabular}{|c|c|c|c|c|c|c|}
\hline No. & $\begin{array}{c}\text { PVP } \\
\text { w/wt }\end{array}$ & Q & D & V & d & Defects \\
\hline 7 & 8 & 6 & 10 & 5.7 & 0.22 & B, Bif \\
\hline 8 & 10 & 0.5 & 15 & 5.5 & 0.57 & B \\
\hline 9 & 12 & 0.5 & 15 & 5.6 & 0.66 & DD, C \\
\hline 10 & 12 & 0.5 & 20 & 5.4 & 1 & C \\
\hline 11 & 14 & 0.5 & 16 & 5.2 & 1.22 & --- \\
\hline 12 & 14 & 0.5 & 20 & 6 & 0.6 & DD \\
\hline
\end{tabular}

TABLE III

PARAMETERS AND RESULTS FOR THE ETHANOL WITH DMF SOLUTIONS

\begin{tabular}{|c|c|c|c|c|c|c|}
\hline No. & $\begin{array}{c}\text { PVP } \\
\text { w/wt }\end{array}$ & Q & D & V & d & Defects \\
\hline 13 & 8 & 5 & 20 & 6 & 0.73 & B \\
\hline 14 & 8 & 5 & 17 & 6 & 1.35 & -- \\
\hline
\end{tabular}

For sample No. 5, a mean of 40.08 MPa for the Young's modulus was obtained, with a standard deviation of 7.4 MPa. Sample No. 11 had a mean of $8.8 \mathrm{MPa}$ for the Young's modulus, with a standard deviation of 2.1 MPa. With sample No. 14, a mean Young's modulus of 32.78 MPa was measured, with a standard deviation of $20.7 \mathrm{MPa}$. Fig. 7, 9, and 11 show all the measured values for the elastic modulus with their corresponding mean, for samples 5, 11, and 14, correspondingly, while Fig. 8, Fig. 10, and Fig. 12 present the histogram of frequencies for their respective sample.

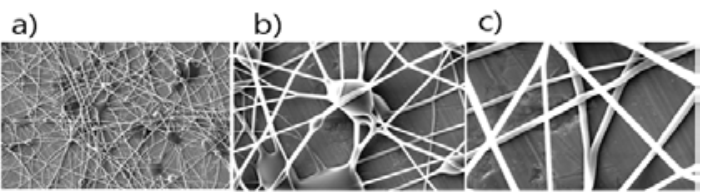

Fig. 1. Micrographs of sample No. 1, ethanol and 4\% wt PVP. a) 1000x, b) 5000x, c) 10000x. Beads and bifurcated fibers are observed, as well as a low concentration of fibers.

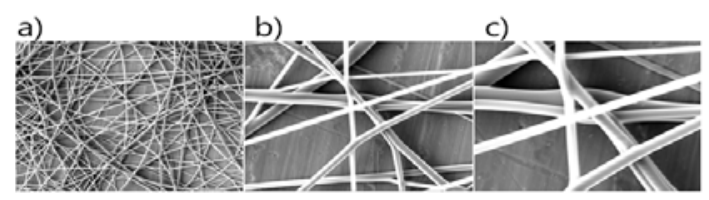

Fig. 2. Micrographs of sample No. 4, ethanol and 6\% wt PVP. a) 1000x, b) $5000 x$, c) $10000 x$. Bifurcated non-acceptable fibers are observed.

Making a comparison among the three solutions analyzed, the one that had the greater Young's modulus was sample No. 5, which used ethanol and 8\% wt PVP. The one with the lowest standard deviation is sample No. 11, made of DMF and $14 \%$ wt PVP. The solution which used a combination of the two solvents still had a greater mean Young's modulus than the one that used only DMF. a)

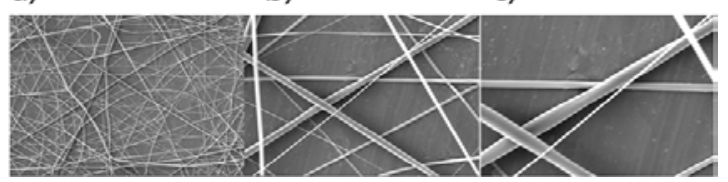

Fig. 3. Micrographs of sample No. 10, DMF and $12 \%$ wt PVP. a) 1000x, b) $5000 x$, c) $10000 x$. There is a low concentration of fibers.

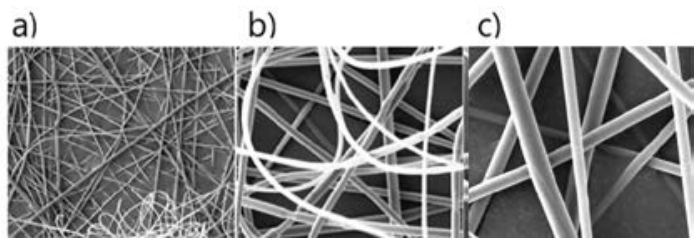

Fig. 4. Micrographs of sample No. 5, ethanol and 8\% wt PVP. a) 1000x b) $5000 \mathrm{x}$ y c) $10000 \mathrm{x}$. Fibers are homogeneous, uniform, without beads or bifurcations, and the concentration is adequate.

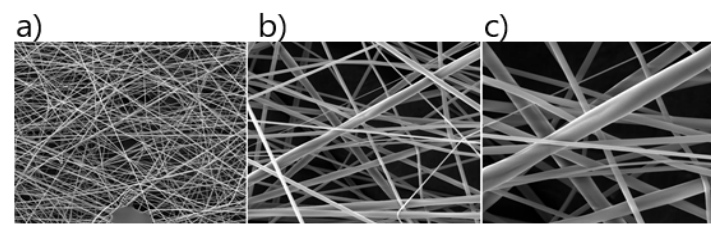

Fig. 5. Micrographs of sample No. 11, DMF and $14 \%$ wt PVP. a) $1000 x$ b) 5000x y c) 10000x. Fibers are uniform, without beads or bifurcations, the diameters are similar, and the concentration is adequate.

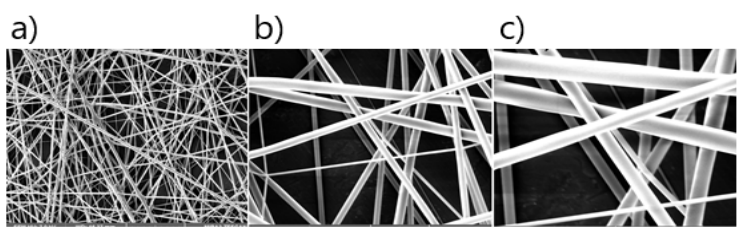

Fig. 6. Micrographs of sample No. 14, ethanol with DMF and 8\% wt PVP. a) $1000 x$, b) $5000 x$ y c) $10000 x$. Fibers are uniform, without beads or bifurcations, the diameters are similar, and the concentration is adequate.

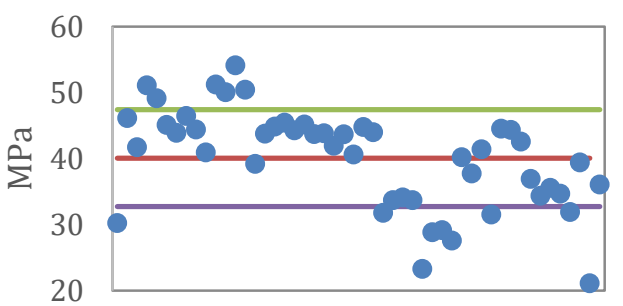

Fig. 7. Young's modulus mean value and standard deviation, corresponding to a solution of ethanol and $8 \%$ wt PVP.

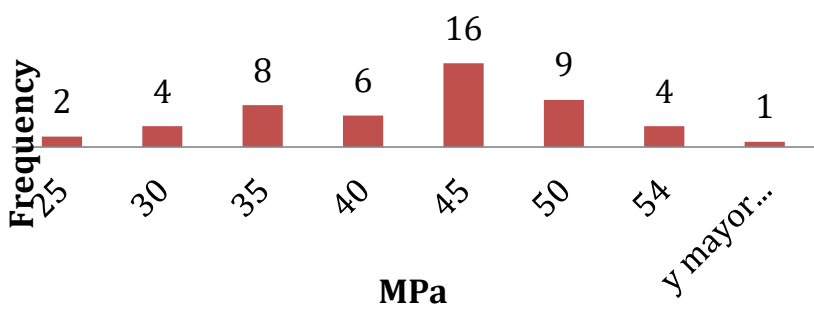

Fig. 8. Histogram of frequencies corresponding to a solution of ethanol and $8 \%$ wt PVP. 


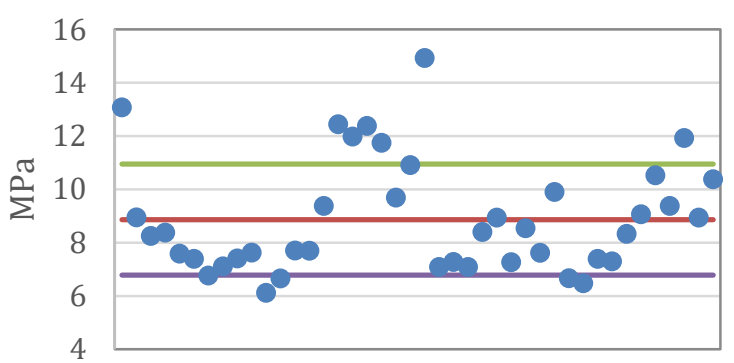

Fig. 9. Young's modulus mean value and standard deviation, corresponding to a solution of DMF and 14\% wt PVP.

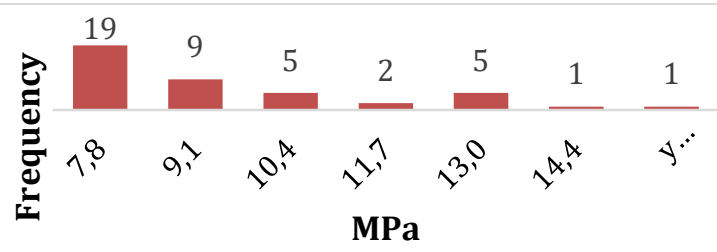

Fig. 10. Histogram of frequencies corresponding to a solution of DMF and $14 \%$ wt PVP.

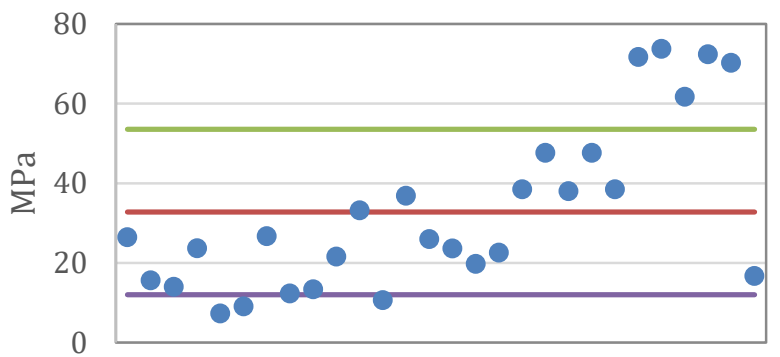

Fig. 11. Young's modulus mean value and standard deviation, corresponding to a solution of ethanol and DMF in a 70/30 ratio and $8 \% \mathrm{wt}$ PVP.

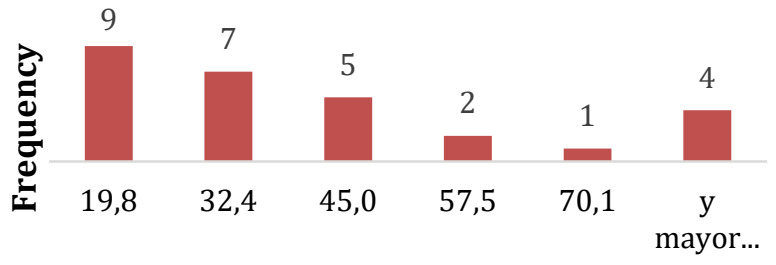

MPa

Fig. 12. Histogram of frequencies corresponding to a solution of ethanol and DMF in a $70 / 30$ ratio and $8 \%$ wt PVP.

For the histograms of frequencies corresponding to samples 11 and 14, if a distribution were drawn, it would be biased to the left. In contrast, sample 5 could be considered an almost symmetric distribution.

\section{CONCLUSIONS}

The morphological characterization of fibers with solutions of PVP with two types of solvents was carried out in the present work, being the solvents ethanol and DMF, respectively. Different parameters were modified to obtain homogeneous fibers, such as weight percent, feed rate, voltage, and distance from needle's tip to collector. The parameter that affected the diameter the most was the weight percent; the weight percent and the diameter having a directly proportional relation. Even though the jet was stable for each one of the solutions tested, only three of them gave flawless fibers: ethanol with $8 \%$ wt PVP (3 ml/h feed rate, $15 \mathrm{~cm}$ distance to collector, $6 \mathrm{kV}$ voltage), DMF with $14 \%$ wt PVP $(0.5 \mathrm{ml} / \mathrm{h}$ feed rate, $20 \mathrm{~cm}$ distance to collector, 6 $\mathrm{kV}$ voltage), and ethanol with DMF in a weight ratio 70/30 and $8 \%$ wt PVP $(5 \mathrm{ml} / \mathrm{h}$ feed rate, $17 \mathrm{~cm}$ distance to collector, $6 \mathrm{kV}$ voltage). The corresponding mean diameters were $1.6 \mu \mathrm{m}, 1.22 \mu \mathrm{m}$, and $1.35 \mu \mathrm{m}$. For all these successful fibers, a mechanical characterization was performed in an AFM to determine the Young's modulus. The results were 40.08 $\mathrm{MPa}$, 8.8 $\mathrm{MPa}$, and $32.78 \mathrm{MPa}$, for the elastic modulus for ethanol, DMF, and ethanol-DMF, respectively. The standard deviations varied from $15 \%$ to $50 \%$ of the mean value, which is acceptable in these kinds of experiments in which there is a lot of uncertainty due to the random deposition of fibers. Being the value of ethanol the greatest, for better mechanical properties, ethanol must be used as the solvent in PVP solutions.

\section{ACKNOWLEDGMENTS}

This investigation could not have been carried out without the assistance of the laboratories of "Reología y Fluidos Complejos” and Microscopy at Universidad de las Fuerzas Armadas ESPE.

\section{REFERENCES}

[1] Doshi, J. \&Reneker, D. H. (1995). Electrospinning Process and Applications of Electrospun Fibers. ELSEVIER, 1.

[2] Agarwal, S., Burgard, M., Greiner, A., \& Wendorff, J. (2016). Electrospinning: A Practical Guide to Nanofibers. Walter de Gruyter $\mathrm{GmbH} \& \mathrm{Co} \mathrm{KG}$.

[3] Li, Z., \& Wang, C. (2013). One-dimensional nanostructures: electrospinning technique and unique nanofibers. New York, NY, USA: Springer.

[4] Megelski, S., Stephens, J. S., Chase, D. B., \&Rabolt, J. F. (2002) Micro-and nanostructured surface morphology on electrospun polymer fibers. Macromolecules, 35(22), 8456-8466.

[5] Son, W. K., Youk, J. H., Lee, T. S., \& Park, W. H. (2004). The effects of solution properties and polyelectrolyte on electrospinning of ultrafine poly (ethylene oxide) fibers. polymer, 45(9), 2959-2966.

[6] Wannatong, L., Sirivat, A., \&Supaphol, P. (2004). Effects of solvents on electrospun polymeric fibers: preliminary study on polystyrene. Polymer International, 53(11), 1851-1859.

[7] Jarusuwannapoom, T., Hongrojjanawiwat, W., Jitjaicham, S., Wannatong, L., Nithitanakul, M., Pattamaprom, C., Koombhongse, P., Rangkupan, R. \&Supaphol, P. (2005). Effect of solvents on electro-spinnability of polystyrene solutions and morphological appearance of resulting electrospun polystyrene fibers. European Polymer Journal, 41(3), 409-421.

[8] Wu, X., Wang, L., Yu, H., \& Huang, Y. (2005). Effect of solvent on morphology of electrospinning ethyl cellulose fibers. Journal of Applied Polymer Science, 97(3), 1292-1297.

[9] Choktaweesap, N., Arayanarakul, K., Aht-Ong, D., Meechaisue, C., \&Supaphol, P. (2007). Electrospun gelatin fibers: effect of solvent system on morphology and fiber diameters. Polymer journal, 39(6), 622-631.

[10] Casasola, R., Thomas, N. L., Trybala, A., \&Georgiadou, S. (2014). Electrospun poly lactic acid (PLA) fibres: effect of different solvent systems on fibre morphology and diameter. Polymer, 55(18), 47284737.

[11] Iwamoto, S., Kai, W., Isogai, A., \& Iwata, T. (2009). Elastic modulus of single cellulose microfibrils from tunicate measured by atomic force microscopy. Biomacromolecules, 10(9), 2571-2576.

[12] Veleirinho, B., Rei, M. F., \&Lopes-DA-Silva, J. A. (2008). Solvent and concentration effects on the properties of electrospun poly (ethylene terephthalate) nanofiber mats. Journal of Polymer Science Part B: Polymer Physics, 46(5), 460-471.

[13] Monar, D. Redrovan, P., Vaca, A., Carrion, L., Narvaez, C., \& Arroyo, C. (2017). Preparation of Monodispersed Polyvinylpyrrolidone Particles by Using the Electrospray Technique. Universidad de las Fuerzas Armadas ESPE, Ecuador. 